\title{
Investigating Miniaturized Electrodynamic Tethers for Picosatellites and Femtosatellites
}

\author{
Iverson C. Bell, III* and Brian E. Gilchrist $\stackrel{ \pm}{-}$ \\ University of Michigan, Ann Arbor, Michigan 48109 \\ and \\ Jesse K. McTernan \\ Pennsylvania State University, University Park, Pennsylvania 16802
}

DOI: $\underline{10.2514 / 1 . A 33629}$

\begin{abstract}
The success of nanosatellites (1-10 kg) and the miniaturization of sophisticated low-power electronics has motivated interest in even smaller "smartphone"-sized spacecraft as either standalone spacecraft or elements in a maneuverable fleet. These spacecraft, known as picosatellites (100 g-1 kg) and femtosatellites (less than $100 \mathrm{~g}$ ), have the potential to enable missions requiring a distributed fleet of sensor spacecraft (for example, distributed aperture, simultaneous spatial sampling, etc.). However, without some degree of propulsion capability, these spacecraft would behave more as an uncontrolled swarm than as a coordinated formation. Furthermore, lifetime in low Earth orbit can be limited for low-mass spacecraft with high area-to-mass ratios. This paper shows that a relatively short (few meters) electrodynamic tether is capable of providing picosatellites and femtosatellites with propellantless drag cancellation and even the ability to change orbit over an altitude range determined by the ionospheric density, neutral atmosphere drag, and magnetic field strength and orientation. The ability of the electrodynamic tether system's anode to draw current from the Earth's ionosphere and generate thrust is estimated, and this performance is traded against the power needed to overcome atmospheric drag forces. The trade study includes the development of a system concept and mission scenario to evaluate electrodynamic-tether propulsion system performance in low Earth orbit, which can be adapted to other planets.
\end{abstract}

\begin{tabular}{ll} 
& \multicolumn{1}{c}{ Nomenclature } \\
$A$ & $=$ cross-sectional area, $\mathrm{m}^{2}$ \\
$A_{\text {anode }}$ & $=$ anode surface area, $\mathrm{m}^{2}$ \\
$A_{\mathrm{sa}}$ & $=$ solar array area, $\mathrm{m}^{2}$ \\
$a_{\mathrm{FN}}$ & $=$ Fowler-Nordheim current coefficient, $\mathrm{A} \cdot \mathrm{V}^{-2}$ \\
$B$ & $=$ magnetic field flux density, $\mathrm{T}$ \\
$b_{\mathrm{FN}}$ & $=$ Fowler-Nordheim voltage coefficient, $\mathrm{V}$ \\
$C_{d}$ & $=$ drag coefficient; 2.2 \\
$D$ & $=$ solar array degradation per year \\
$E$ & $=$ elastic modulus, Pa \\
$\boldsymbol{E}_{\mathrm{amb}}$ & $=$ electric field, $\mathrm{V} \cdot \mathrm{m}^{-1}$ \\
$F_{\mathrm{drag}}$ & $=$ drag force, $\mathrm{N}$ \\
$F_{\mathrm{EDTdrag}}$ & $=$ drag force on the tether, $\mathrm{N}$ \\
$F_{\mathrm{gg}}$ & $=$ gravity-gradient force, $\mathrm{N}$ \\
$F_{\mathrm{Lorentz}}$ & $=$ Lorentz force, $\mathrm{N}$ \\
$F_{\mathrm{scdrag}}$ & $=$ drag force on the spacecraft, $\mathrm{N}$ \\
$F_{\mathrm{tether}}$ & $=$ electrodynamic tether thrust, $\mathrm{N}$ \\
$I_{d}$ & $=$ inherent degradation \\
$I_{\mathrm{FN}}$ & $=$ cathode electron emission current, $\mathrm{A}$ \\
$I_{\text {tether }}$ & $=$ tether current, $\mathrm{A}$ \\
$I_{\mathrm{WLP}}$ & $=$ anode electron collection current, $\mathrm{A}$ \\
$k$ & $=$ Boltzmann constant, $1.38 \times 10^{-23} \mathrm{~J} \cdot \mathrm{K}^{-1}$ \\
$L$ & $=$ tether length, $\mathrm{m}$
\end{tabular}

Received 12 April 2016; revision received 18 July 2016; accepted for publication 15 August 2016; published online 27 October 2016. Copyright $\odot$ 2016 by the authors. Published by the American Institute of Aeronautics and Astronautics, Inc., with permission. All requests for copying and permission to reprint should be submitted to CCC at www.copyright.com; employ the ISSN 0022-4650 (print) or 1533-6794 (online) to initiate your request. See also AIAA Rights and Permissions www.aiaa.org/randp.

*Postdoctoral Fellow, Electrical Engineering, 1301 Beal Ave. Student Member AIAA.

${ }^{\dagger}$ Professor, Electrical Engineering and Computer Science, 1301 Beal Ave. Associate Fellow AIAA.

${ }^{\ddagger}$ Graduate Student Research Assistant, Aerospace Engineering, 229 Hammond Building. Student Member AIAA.

${ }^{\S}$ Professor, Engineering Design, Electrical Engineering, and Aerospace Engineering, 213 Hammond Bldg. Associate Fellow AIAA.

$L_{\mathrm{cg}}$
$L_{D}$
$L_{i}$
$m_{\mathrm{EDT}}$
$m_{\mathrm{e}}$
$m_{\mathrm{sc}}$
$n_{\mathrm{e}}$
$P_{\mathrm{BOL}}$
$P_{\mathrm{EDT}}$
$P_{\mathrm{EOL}}$
$P_{\text {prop }}$
$q$
$R_{\text {curve-min }}$
$r_{\text {cg }}$
$r_{\mathrm{EDT}}$
$T_{d}$
$T_{e}$
$T_{\text {ecl }}$
$V_{\text {anode }}$
$V_{\text {cathode }}$
$V_{\text {emf }}$
$V_{\text {float }}$
$V_{\text {gate }}$
$V_{\text {iono }}$
$V_{\text {orb }}$
$X_{d}$
$X_{\text {ecl }}$
$y_{\text {max }}$
$\eta_{\text {conv }}$
$\eta_{\text {dc }}$
$\eta_{\mathrm{ITO}}$
$\eta_{\text {prop }}$
$\theta_{\text {sun }}$
$\mu$
${ }$

$=$ distance between the spacecraft and the center of gravity of the tethered system, $m$

$=$ life degradation

$=$ satellite lifetime, year

$=$ tether mass, $\mathrm{kg}$

$=$ electron mass, $\mathrm{kg}$

$=$ spacecraft mass, $\mathrm{kg}$

$=$ electron density, $\mathrm{m}^{-3}$

= beginning-of-life solar array power output, $\mathrm{W}$

$=$ power consumed by tether propulsion, $\mathrm{W}$

$=$ end-of-life solar array power output, $\mathrm{W}$

$=$ propulsion power generated by the spacecraft, $\mathrm{W}$

$=$ elementary charge; $1.6 \times 10^{-19} \mathrm{C}$

$=$ minimum radius of curvature, $\mathrm{m}$

$=$ distance between the center of the Earth and the center of gravity, $\mathrm{m}$

$=$ tether radius, $\mathrm{m}$

$=$ fraction of the orbit spent in daylight

$=$ electron temperature, $\mathrm{K}$

$=$ fraction of the orbit spent in eclipse

$=$ anode power supply voltage, $\mathrm{V}$

$=$ cathode power supply voltage, $\mathrm{V}$

$=$ motional electromotive force, $\mathrm{V}$

$=$ floating potential, $\mathrm{V}$

$=$ gate voltage relative to electron emitting structure, $\mathrm{V}$

$=$ voltage drop across the ionosphere, $\mathrm{V}$

$=$ orbital velocity, $\mathrm{m} \cdot \mathrm{s}^{-1}$

$=$ efficiency of electrical power distribution during daylight

$=$ efficiency of electrical power distribution during eclipse

$=$ maximum lateral displacement of a bowed tether, $\mathrm{m}$

$=$ solar panel energy conversion efficiency

$=\mathrm{dc}-\mathrm{dc}$ conversion efficiency

$=$ efficiency due to cover glass with indium tin oxide coating

$=$ fraction of spacecraft power available for propulsion

$=$ average solar angle, deg.

$=$ standard gravitational parameter of Earth; $3.986 \times$ $10^{14} \mathrm{~m}^{3} \cdot \mathrm{s}^{-2}$ 


$\begin{array}{ll}\rho & =\text { atmospheric neutral density, } \mathrm{kg} \cdot \mathrm{m}^{-3} \\ \sigma_{y} & =\text { yield strength, Pa } \\ \Phi_{\text {albedo }} & =\text { average flux of Earth albedo; } 410 \mathrm{~W} \cdot \mathrm{m}^{-2} \\ \Phi_{\text {anode }} & =\text { anode sheath potential, } \mathrm{V} \\ \Phi_{\text {sun }} & =\text { average direct solar radiation flux; } 1368 \mathrm{~W} \cdot \mathrm{m}^{-2}\end{array}$

\section{Introduction}

$\mathbf{T}$ HE development of subkilogram-scale smartphone-sized spacecraft with the longest dimensions in the tens of centimeters and, more recently, down to a few centimeters is motivated by the success of nanospacecraft (1-10 kg) [1-3] and advances in electronics miniaturization and reduced power consumption. Improvements in integrated circuit (IC) and microelectromechanical system technology are making possible the concept of very small spacecraft at the levels of fully monolithic semiconductor ICs or hybrid ICs [4-7]. These spacecraft can be categorized as picosatellites $(100 \mathrm{~g}-1 \mathrm{~kg})$ and femtosatellites (less than $100 \mathrm{~g}$ ), which are also referred to as

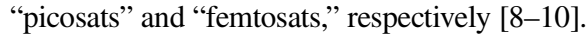

Small, highly capable, sensor spacecraft could provide the ability to perform missions requiring distributed measurements in space and/or time (e.g., distributed aperture, simultaneous spatial sampling, or rapid resampling of a single location) [10]. A coordinated fleet of picosats and femtosats could enable, for example, global observation and monitoring to enhance disaster awareness, preparedness, and response (e.g., earthquake, forest fire, hurricane) [11,12]; distributed in situ sensing of the ionosphere or magnetosphere (e.g., ionospheric depletion regions, magnetotail behavior, upper atmosphere monitoring) $[13,14]$; and synthesizing virtual apertures for highresolution remote sensing $[15,16]$. Additional viable and useful applications for fleets of picosats and femtosats are described in $[10,17]$.

Without some degree of propulsion and attitude control, however, these spacecraft would behave more like an uncontrolled swarm rather than as a coordinated formation. For example, naturally occurring environmental effects, like atmospheric drag and solar radiation pressure, have an especially strong influence on the dynamics of spacecraft at this size and mass scale because of their relatively high area-to-mass ratios [18]. As a result, the orbital lifetimes of these spacecraft in low Earth orbit (LEO) would be limited and variable from spacecraft to spacecraft due to atmospheric drag effects [19].

Although spacecraft using a chemical or electric propulsion system with proper attitude pointing may be able to overcome the continuous force of atmospheric drag, the mass and volume of propellant required would increase with the spacecraft's intended lifetime. Chemical and electric propulsion technologies that have been appropriately scaled for small spacecraft were described in [20]. Alternatively, a propulsion technology that does not require fuel or propellant could be used to maintain orbit over the spacecraft's operational lifetime as well as allow formations of picosats and femtosats to be dynamically maneuvered. The Sprite spacecraft, a milligram-level millimeter-scale architecture, explored propellantless maneuvering using the solar radiation pressure force [21]. Also exploiting solar radiation pressure, Lücking et al. [22] explored the use of an electrochromic coating on an ultrasmall spacecraft to facilitate solar sailing. Additionally, Peck et al. [23] studied the potential to propellantlessly alter the orbit of a charged spacecraft as it traveled through a planetary magnetic field.

The objective of this paper is to investigate the potential of short (few meters long), semirigid electrodynamic tethers (EDTs) to provide propellantless propulsion to picosats and femtosats. Studies presented in [19] suggested that EDTs were capable of enhancing the maneuverability of spacecraft at this scale. Our goal is to build on [19] and explore the feasibility of using miniaturized EDTs for picosat and femtosat propulsion. In the first three sections, we describe the miniaturized EDT concept, the trade study, and the miniaturized EDT circuit model. In Sec. V, we estimate the average electrical power that picosats and femtosats can generate for propulsion. In Sec. VI, we compare this with the average power required for drag makeup. In Secs. VII and VIII, we calculate EDT thrust, compare this with other dominant forces on the tethered spacecraft, and simulate boosting in orbit. In Sec. IX, we briefly describe a space mission being planned to evaluate this concept in the orbital environment.

\section{Miniaturized Electrodynamic Tether Background}

This section discusses the basic principles of EDT technology. EDTs are capable of providing propellantless (or, in some cases, nearly propellantless) orbit maneuvering and offer a variety of other features that can be mission enabling. Here, we explain these capabilities, introduce the miniaturized EDT system concept, and describe some of its characteristics.

\section{A. EDT Fundamentals}

An electrodynamic tether, or EDT, is a long, thin conductor attached to a spacecraft. As the EDT crosses magnetic field lines, the Lorentz force acts on electrons in the tether. The Lorentz force on charged particles is [24]

$$
\boldsymbol{F}_{\text {Lorentz }}=q\left(\boldsymbol{E}_{\text {amb }}+\boldsymbol{V}_{\text {orb }} \times \boldsymbol{B}\right)
$$

where $q$ is the particle charge, $\boldsymbol{E}_{\mathrm{amb}}$ is the ambient electric field, $\boldsymbol{B}$ is the magnetic field flux density, $\boldsymbol{V}_{\text {orb }}$ is the spacecraft orbital velocity, and $\boldsymbol{V}_{\text {orb }} \times \boldsymbol{B}$ is the motional electromotive force (emf). The magnitude of the ambient electric field in the equatorial and midlatitude region of the ionosphere is on the order of $\sim 0-3 \mathrm{mV} \cdot \mathrm{m}^{-1}$ [25-27], which is less than $5 \%$ of the induced motional emf of a vertically aligned tether, so $\boldsymbol{E}_{\mathrm{amb}}$ is ignored. The emf potential across the tether can thus be represented as [24]

$$
V_{\mathrm{emf}} \approx-\int_{0}^{L} \boldsymbol{V}_{\mathrm{orb}} \times \boldsymbol{B} \cdot \mathrm{d} \boldsymbol{L}
$$

where $\mathrm{d} \boldsymbol{L}$ is a differential vector increment of length along the tether, and $L$ is the total tether length. The geomagnetic field rotates with the Earth, so the velocity used to calculate motional emf should be in the reference frame of the Earth's rotation (discussed in Sec. III.C). Cutting across magnetic field lines at orbital velocities of about $7 \overline{500} \mathrm{~km} \cdot \mathrm{s}^{-1}$, which is typical for LEO, the magnitude of the motional electric field will be $\sim 0.1-0.3 \mathrm{~V} \cdot \mathrm{m}^{-1}$. It should be noted that $V_{\text {emf }}$ can vary over an orbit because of tether libration and variation in the angle between the magnetic field and velocity vectors.

If the EDT is able to electrically connect to the surrounding ionospheric plasma at each end, the ionosphere can serve as a path to "complete the circuit," enabling current flow through the tether. The current in the EDT interacts with the ambient magnetic field to produce a propulsive force

$$
\boldsymbol{F}_{\text {tether }}=\int_{0}^{L} I_{\text {tether }} \mathrm{d} \boldsymbol{L} \times \boldsymbol{B}
$$

where $I_{\text {tether }}$ is the tether current in segment $\mathrm{d} \boldsymbol{L}$. In LEO, the thrust generated by the emf opposes motion, lowering the altitude over time. A power supply on board the spacecraft with a voltage exceeding the emf can reverse the current and the direction of thrust, generating a boosting force. Depending on the orientation of the tether relative to the magnetic field, there may be an out-of-plane thrust component, producing inclination change. By managing the flow of electrical current conducted by the tether and where thrust is applied along the orbit, an EDT can produce thrust to boost, deboost, or change inclination.

A tethered satellite system also experiences the gravity-gradient force and torque, which provide relative stability along the local vertical and generate tension. The magnitude of the gravity-gradient force is approximated as [28]

$$
F_{\mathrm{gg}} \approx 3 L_{\mathrm{cg}} m_{\mathrm{sc}} \frac{\mu}{r_{\mathrm{cg}}^{3}}
$$

where $m_{\mathrm{sc}}$ is the mass of the spacecraft; $L_{\mathrm{cg}}$ is the distance between the tether system's center of gravity and the spacecraft; $r_{\mathrm{cg}}$ is the 
distance between the center of the Earth and the center of gravity of the tethered system; and $\mu$ is the standard gravitational parameter ( $\mu=398,600 \mathrm{~km}^{3} \cdot \mathrm{s}^{-2}$ for Earth).

\section{B. Miniaturized EDT System Concept Description}

The miniaturized EDT system concept considered in this paper is a short (few meters long), fully insulated, conducting tether connecting a pair of nearly identical picosats or femtosats that work together as a single unit [19]. Figure 1 shows an illustration of the system concept. Each spacecraft in the tethered pair has solar panels, energy storage capability, a power supply, a cold cathode electron emitter, and capability to collect electrons on its surface. In this configuration, tether current can be reversed to change the direction of the propulsive force.

The miniaturized EDT is a fundamentally novel paradigm because it is much shorter than a conventional EDT, with total length of about 10-20 m, and the tethered end masses are small, subkilogram spacecraft. In contrast, previously proposed "short-tether" concepts were 100-1000 $\mathrm{m}$ in length and had 10-100 kg end masses [29-33]. The system concept discussed in this paper is also novel because it considers the use of a semirigid tether, which is explained in Sec. II.C. Additional miniaturized EDT properties are identified throughout the paper.

\section{Tether Semirigidity}

For the purposes of this study, the relatively short EDT considered here is assumed to be a "semirigid" structure. By this, we mean that the tether has both flexural rigidity to limit large tether deflection on orbit and flexibility for compact storage (e.g., coiled up). This is in contrast to much longer, flexible tether systems with more massive end bodies, in which the gravity-gradient force would generate the tension necessary for stability and "straightness" in the presence of lateral forces (i.e., drag, thrust, and solar radiation pressure). These forces can cause tether bowing when the gravity-gradient force does not provide the necessary tension, which can be the case for short tethers connecting extremely low-mass spacecraft [34]. Significant bowing reduces the vertical length of the tether, decreasing net thrust. A sufficient level of flexural rigidity may be important for a tether to resist large deflection on orbit. The semirigidity analysis presented here informs the types of tether materials as well as the range of tether diameters that are considered later in the trade study. Other necessary tether properties are identified throughout the paper.

Atmospheric drag effects in LEO can cause bowing. The magnitude of the drag force is

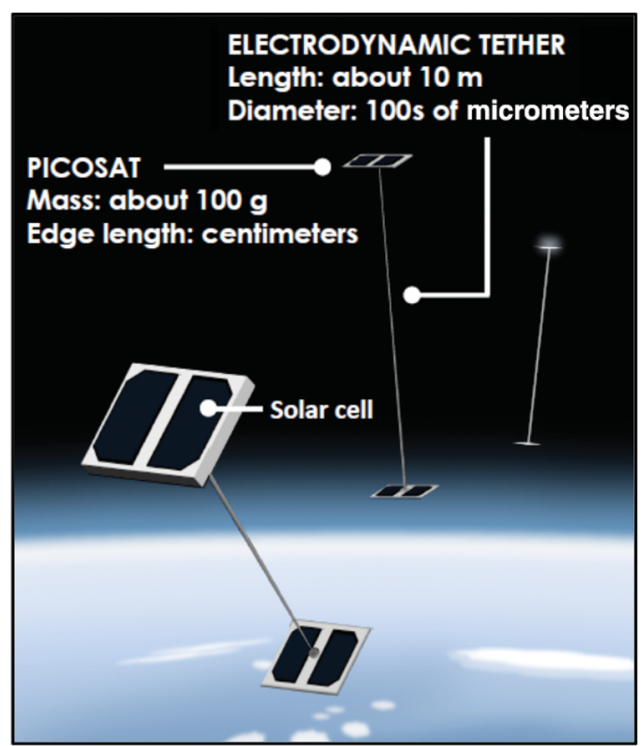

Fig. 1 Concept of miniaturized electrodynamic tether connecting pairs of picosats and orbiting as a maneuverable fleet [19].

$$
F_{\text {drag }}=\frac{1}{2} \rho C_{D} A V_{\text {orb }}^{2}
$$

where $A$ is the cross-sectional area, $C_{D}$ is the drag coefficient, and $\rho$ is the atmospheric density. The atmosphere in LEO corotates with the Earth, so the velocity used to calculate drag should be in the reference frame of the Earth's rotation (discussed in Sec. III.C). Although drag acts on the entire EDT-spacecraft system, tethers are long, thin, and lightweight, so they typically have higher area-to-mass ratios than the spacecraft pair they connect. As a result, EDTs experience stronger acceleration due to drag. Transforming the orbiting EDT into an equivalent static system and assuming that 1) the drag force is uniform along the tether, 2) the tethered spacecraft have identical masses and experience equal drag forces, and 3) the tether is free to rotate at the tether-spacecraft connections, the EDT system can be modeled as a simply supported beam [34]. The details of this derivation can be found in [35]. The maximum tether deflection, occurring at the middle of the tether, is

$$
y_{\max }=\frac{40 L^{3}}{384 \pi E r_{\mathrm{EDT}}^{4}}\left(\frac{F_{\mathrm{EDTdrag}} m_{\mathrm{sc}}-F_{\mathrm{scdrag}} m_{\mathrm{EDT}}}{2 m_{\mathrm{sc}}+m_{\mathrm{EDT}}}\right)
$$

where $m_{\mathrm{EDT}}$ is the tether mass, $F_{\mathrm{EDTdrag}}$ is the drag on the tether, $F_{\text {scdrag }}$ is the drag on the spacecraft, $r_{\mathrm{EDT}}$ is the radius of the EDT, and $E$ is the elastic modulus. Deflection is inversely proportional to $E$, so a material with a relatively large $E$ can be used to reduce bowing. Moreover, $y_{\max }$ is inversely proportional to $r_{\mathrm{EDT}}^{4}$, so increasing tether radius decreases bowing. To keep deflection relatively small (here, $y_{\max } \leq 0.05 L$ ) for the range of tether lengths considered in the study, the tether radii used here scale with $L^{3 / 4}$. When the tether is sufficiently long, the gravity-gradient force may be able produce sufficient tension to reduce bowing, even for a flexible tether [34]. Thus, EDTs with smaller radii and/or composed of lower $E$ materials can be considered when the gravity-gradient force dominates over other forces, although the specific criterion for the gravity-gradient force to dominate is not calculated here. The approach of spinning the tethered system about the center of mass to increase tension in the tether has been proposed for other systems [29] but, for simplicity, this was not considered here.

To store the tether in a coiled shape before tether deployment without risking permanent deformation, it is necessary to calculate the minimum radius of curvature that the tether can experience without exceeding the material's yield strength $\sigma_{y}$. Assuming the EDT will experience uniform bending in storage, the minimum radius of curvature $R_{\text {curve-min }}$ that can be applied to an EDT of wire radius $r_{\mathrm{EDT}}$ before plastic deformation occurs is [36]

$$
R_{\text {curve-min }}=\frac{E}{\sigma_{y}} r_{\mathrm{EDT}}
$$

The conclusion here is that a tether material with a relatively high yield stress may be desired in order that the minimum radius of curvature is relatively small.

\section{Trade Study Background}

The trade study evaluates the ability of the miniaturized EDT system to draw electrical current from the ambient ionosphere and generate thrust. Mission scenarios are also developed to assess orbital maneuvering capability. The purpose of this section is to overview assumptions made in the trade study. Here, key characteristics of the miniaturized EDT, the tethered picosats and femtosats, and the orbital environment are discussed.

\section{A. Tether Materials}

In this section, a possible material is discussed that is representative of what could be used to establish the feasibility of using a short, semirigid tether. It should be noted that the material study is not viewed as exhaustive. It remains for future research to do a more complete study of possible material options. For this paper, it 
Table 1 Properties of tether materials

\begin{tabular}{|c|c|}
\hline Parameter & Value \\
\hline \multicolumn{2}{|l|}{ Monel $^{\circledR} K-500[37]$} \\
\hline Electrical resistivity $\left(21^{\circ} \mathrm{C}\right)$ & $6.15 \times 10^{-7} \Omega \cdot \mathrm{m}$ \\
\hline Mass density & $8.44 \mathrm{~g} \cdot \mathrm{cm}^{-3}$ \\
\hline Elastic modulus, tension $\left(21^{\circ} \mathrm{C}\right)$ & $179 \mathrm{GPa}$ \\
\hline Yield strength, spring temper cold-drawn wire & $\begin{array}{c}896-1241 \mathrm{MPa} \\
\text { (900 MPa assumed) }\end{array}$ \\
\hline \multicolumn{2}{|l|}{ Teflon $^{\circledR}$ PFA film [40] } \\
\hline Dielectric strength & $260 \mathrm{~V} \cdot \mu \mathrm{m}^{-1}$ \\
\hline Mass density & $2.15 \mathrm{~g} \cdot \mathrm{cm}^{-3}$ \\
\hline Elastic modulus, tension $\left(21^{\circ} \mathrm{C}\right)$ & $0.48 \mathrm{GPa}$ \\
\hline Yield strength $\left(21^{\circ} \mathrm{C}\right)$ & $12 \mathrm{MPa}$ \\
\hline
\end{tabular}

was viewed as sufficient to identify candidate materials that appeared to be satisfactory.

The tether assumed here is composed of a central conductor with an external, uniform insulator sheathing. Table 1 summarizes characteristics of these materials. The central conductor is a Monel ${ }^{\circledR}$ K-500 (referred to here as "Monel") [37]. Monel is a high-strength nickel-copper alloy that has a high elastic modulus and yield strength. The high yield strength allows the tether to be bent at relatively small radii of curvature. In addition, the high elastic modulus of the material allows the tether to be made relatively thin without experiencing significant bowing in orbit. Monel also has good high-temperature performance: the elastic modulus does not reduce by more than $1 \%$ from 0 to $300^{\circ} \mathrm{C}$. Moreover, the elastic modulus increases at lower temperatures [38].

The outer insulator is Dupont ${ }^{\mathrm{TM}}$ Teflon ${ }^{\circledR}$ perfluoroalkoxy alkane (PFA) (referred to here as "Teflon"). Teflon has a high dielectric strength and ultraviolet (UV) radiation resistance, as well as relatively low reactivity with atomic oxygen [38-40]. The high dielectric strength allows a very thin layer of Teflon to be used, but mechanical robustness may require thicker layers. It is assumed here that the insulation is $12.5 \mu \mathrm{m}(0.5 \mathrm{mil})$ thick. This is many times the minimum thickness needed to prevent electrical breakdown. Teflon typically has a low coefficient of static friction, but it can be treated to make it adhere more easily.

\section{B. Picosatellite and Femtosatellite Characteristics}

It is important to specify the size, shape, and mass of the tethered picosats and femtosats to be used in the study. These qualities influence orbital lifetime, which in turn establishes the required thrust for drag makeup and the ability to change orbital parameters. In addition, the size and shape of a spacecraft affect the electrical power that can be generated by surface-mounted solar cells and that can be used for propulsion. Finally, the gravity-gradient force, which provides tether tension and attitude stability, is proportional to the mass of the spacecraft.

The representative spacecraft selected for this study were influenced by existing and proposed femtosat and picosat designs. Illustrations of the femtosats and picosats are shown in Fig. 2. Table 2 lists their dimensions. The largest spacecraft considered, a $200 \mathrm{~g}$ planar picosat, is approximately the same size as PCBSat, which is a picosat developed by the University of Surrey [41]. This shape would offer relatively large, flat faces for mounting solar cells and low drag

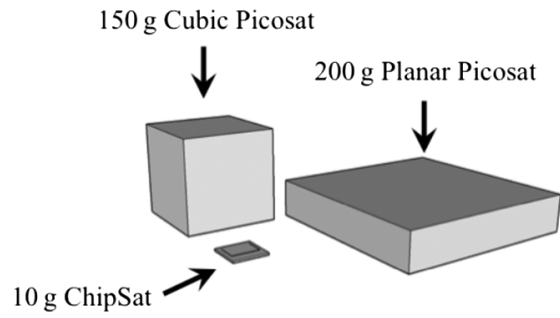

Fig. 2 Illustration depicting the picosats and femtosat considered in this study.
Table 2 Mass and dimensions of spacecraft considered in the trade study

\begin{tabular}{lcc}
\hline \hline Description & Dimensions, cm & $\begin{array}{c}\text { Drag area in lowest drag } \\
\text { attitude, } \mathrm{cm}^{2}\end{array}$ \\
\hline 200 g planar picosat & $10 \times 10 \times 2$ & 20 \\
150 g cubic picosat & $5 \times 5 \times 5$ & 25 \\
10 g ChipSat & $2.5 \times 2.5 \times 0.5$ & 1.25 \\
\hline \hline
\end{tabular}

Table 3 Ionospheric and neutral atmosphere conditions

\begin{tabular}{|c|c|c|c|}
\hline Value & $\begin{array}{l}400 \mathrm{~km} \\
\text { altitude }\end{array}$ & $\begin{array}{l}500 \mathrm{~km} \\
\text { altitude }\end{array}$ & $\begin{array}{l}600 \mathrm{~km} \\
\text { altitude }\end{array}$ \\
\hline Electron temperature, $\mathrm{eV}$ & 0.11 & 0.14 & 0.15 \\
\hline $\begin{array}{l}\text { Mass density of the neutral atmosphere, } \\
\mathrm{g} \cdot \mathrm{cm}^{-3}\end{array}$ & $5 \times 10^{-15}$ & $9 \times 10^{-16}$ & $2 \times 10^{-16}$ \\
\hline Electron density, $\mathrm{cm}^{-3}$ & $1 \times 10^{6}$ & $7 \times 10^{5}$ & $3 \times 10^{5}$ \\
\hline Magnetic field, $G$ & 0.3 & 0.3 & 0.3 \\
\hline Circular orbital velocity, $\mathrm{km} \cdot \mathrm{s}^{-1}$ & 7.7 & 7.6 & 7.6 \\
\hline $\begin{array}{l}\text { Atmosphere, ionosphere, magnetic field } \\
\text { eastward rotation speed, } \mathrm{km} \cdot \mathrm{s}^{-1}\end{array}$ & $\sim 0.4$ & $\sim 0.4$ & $\sim 0.4$ \\
\hline Dominant ion species & $\mathrm{O}^{+}$ & $\mathrm{O}^{+}$ & $\mathrm{O}^{+}$ \\
\hline
\end{tabular}

if a low cross-section attitude could be maintained. The middle-sized $150 \mathrm{~g}$ cubic picosat takes its dimensions from the PocketQube architecture [42]. Finally, the much smaller $10 \mathrm{~g}$ ChipSat was inspired by the Sprite femtosat [43].

In this study, we assume that the $10 \mathrm{~g}$ ChipSat and $200 \mathrm{~g}$ planar picosat are in a low drag attitude. One approach to obtaining some degree of passive attitude maintenance for each picosat and femtosat is to design the spacecraft so the center of mass of the spacecraft is offset from the center of pressure along the velocity vector (similar to a badminton shuttlecock). Similar approaches were explored in $[21,44]$ for small spacecraft attitude stability. The degree to which the attitude can be maintained for satellites at this scale is not yet understood. The spacecraft attitude may oscillate around an equilibrium angle relative to the low drag orientation, thus increasing the effective cross-sectional area. It remains for future research to do a more complete study of picosat and femtosat attitude and attitude maintenance. To be clear, here, we are discussing the attitude of the individual picosats and femtosats. Later, we will discuss the attitude of the tethered spacecraft system as a whole.

\section{Orbital Environment}

Earth ionospheric conditions are used as the basis of this study, but the results could easily be extended to other planets with a magnetoplasma such as Jupiter. The peak electron density, and thus EDT thrust capability, occurs in the $F$ region of the ionosphere between 300 and $600 \mathrm{~km}$ altitudes (generally closer to $400 \mathrm{~km}$ ), so the orbital environment in this altitude range is considered in this study $[27,45]$. Preliminary studies exploring this concept suggested that the atmospheric drag in a $300 \mathrm{~km}$-altitude orbit was too large for drag compensation using a short EDT; therefore, in this study, we consider altitudes from 400 to $600 \mathrm{~km}$ [19]. Because vertically oriented EDTs produce peak in-plane thrust near the equatorial plane, the focus here is on low-inclination orbits. Near the equatorial plane in LEO, the magnetic field, the neutral atmosphere, and the ionosphere approximately corotate with the Earth $[27,46]$. With small error, the speed of rotation can be crudely approximated at latitudes close to the equatorial plane in LEO as the rotational speed of the surface of the Earth at the equator, or $\sim 0.4 \mathrm{~km} \cdot \mathrm{s}^{-1}$ [47].

Atmospheric and ionospheric assumptions are summarized in Table 3. Electron densities and temperatures were determined by averaging around an equatorial orbit at altitudes of 400, 500, and $600 \mathrm{~km}$. The 2007 International Reference Ionosphere (IRI) model was used to generate a list of electron densities and temperatures for each altitude, calculating the values at $1^{\circ}$ longitude increments in the equatorial plane. The average electron density and temperature for each altitude are provided in Table $\underline{3}$. The average neutral mass 
density and magnetic flux density were similarly obtained from the mass-spectrometer-incoherent-scatter (MSIS-E-90) model and the International Geomagnetic Reference Field (IGRF-11) models, respectively $[\underline{48,49]}$. All of the models calculated parameters using the date 1 July 2011 because it was a day of high solar activity during solar cycle $23[50,51]$. The drag force scales with neutral density and EDT thrust scales with electron density, and both increase at the solar maximum. However, the neutral-to-electron-density ratio increases during high solar activity, thus making it a worst-case scenario for EDT drag makeup and boosting.

\section{Miniaturized EDT Circuit Model}

The miniaturized EDT system can be modeled by electrical circuit elements representing the tether and other key elements of the circuit, including the anode, cathode, ionospheric plasma, and the motional emf. The EDT circuit is illustrated in Fig. 3. The circuit is a closed current loop, so the sum of the voltages is zero (Kirchhoff's voltage law). A circuit equation consisting of the voltage drops can be written as

$$
\begin{aligned}
0= & V_{\text {anode }}+V_{\text {cathode }}+V_{\text {float }}+V_{\text {gate }}+V_{\text {emf }}+I_{\text {tether }} R_{\text {tether }} \\
& +\Phi_{\text {anode }}+V_{\text {iono }}
\end{aligned}
$$

where $V_{\text {anode }}$ is the anode power supply voltage, $V_{\text {cathode }}$ is the cathode power supply voltage, $V_{\text {float }}$ is the floating potential of the electron emitting spacecraft (the spacecraft opposite the anode), $V_{\text {gate }}$ is the gate voltage relative to the electron emitting structure for a field emitter array cathode, $I_{\text {tether }} R_{\text {tether }}$ is the voltage drop across the tether due to the tether's ohmic resistance, $\Phi_{\text {anode }}$ is the potential difference between the anode and the ambient plasma, and $V_{\text {iono }}$ is the voltage drop across the ionosphere. The impedance in the ionosphere is on the order of a few ohms or less, which is much smaller than other impedances in the EDT circuit, so the voltage drop in the ionosphere is assumed to be negligible here (discussed in Sec. IV.C) [52,53]. Also, although a field emitter array cathode is assumed in this study, other technologies may be considered (discussed in Sec. IV.B). This section explains how the circuit elements in the miniaturized EDT circuit are modeled.

\section{A. Tether and Motional Electromotive Force}

The tether is simply modeled as a resistive element, using the room temperature resistivity of the EDT's conductor, Monel, to calculate resistance. For a $10 \mathrm{~m}$ tether, the resistance would be about $780 \Omega$ for a $125 \mu \mathrm{m}$-diam tether. The necessary current for drag makeup and orbit change results in a small voltage drop relative to other impedances in the circuit. Nonetheless, coating the tether core with a thin, highly conductive material like gold can reduce tether resistance further. The motional emf induced in a tether is described in Sec. II.A and expressed in Eq. (2). The emf for a $10 \mathrm{~m}$ tether is $\sim 1-3 \mathrm{~V}$ in a prograde orbit in LEO, so the power supply voltage required to exceed the emf and boost the EDT is relatively low.

\section{B. Cathode Spacecraft}

Electron emission can be achieved through the use of a field emitter array (FEA) cathode mounted on the surface of one of the tethered satellites. Although an FEA cathode is considered in this study, there are other technologies that deserve further study and comparison. For example, low work function thermionic emitters are another technology worthy of study in future research [54]. In Fig. 3, the upper spacecraft is configured to emit electrons. For a typical FEA cathode, electrons are emitted from an electrode composed of, for example, a twodimensional array of carbon nanotubes or micrometer-scale cones [55,56]. A positively biased grid, or "gate," near the emitting structure establishes an electric field (on the order of $1 \mathrm{~V} \cdot \mathrm{nm}^{-1}$ ) that enables tunneling of electrons out of the emitter tips and into the ambient plasma. The benefits of the field emitter array include its flat-panel scalability, meaning that it has a low profile and can potentially fit into different faces of a small satellite. FEAs are extremely sensitive to surface contamination, so the robustness of FEAs in the space environment remains an open area of research $[57,58]$.

The FEA here is modeled after a Spindt-style $2.5 \times 2.5 \mathrm{~mm}$ array characterized in [59]. The expression for FEA current emission is

$$
I_{\mathrm{FN}}=a_{\mathrm{FN}} V_{\text {gate }}^{2} \exp \left(\frac{-b_{\mathrm{FN}}}{V_{\text {gate }}}\right)
$$

where $V_{\text {gate }}$ is the potential of the gate relative to the cathode; and $a_{\mathrm{FN}}$ and $b_{\mathrm{FN}}$ are the Fowler-Nordheim current and voltage coefficients, respectively, with values of $0.03 \mathrm{~A} \cdot \mathrm{V}^{-2}$ and $487 \mathrm{~V}$, respectively. The values for $a_{\mathrm{FN}}$ and $b_{\mathrm{FN}}$ were determined in laboratory conditions [59]. For this analysis, it is assumed that the cathode emission current is exactly equal to the tether current, that the voltage drop in the cathode emitter is negligible, and that the spacecraft floating potential (cathode spacecraft sheath voltage drop) is approximately $-0.5 \mathrm{~V}$ relative to the plasma potential [60]. The floating potential is

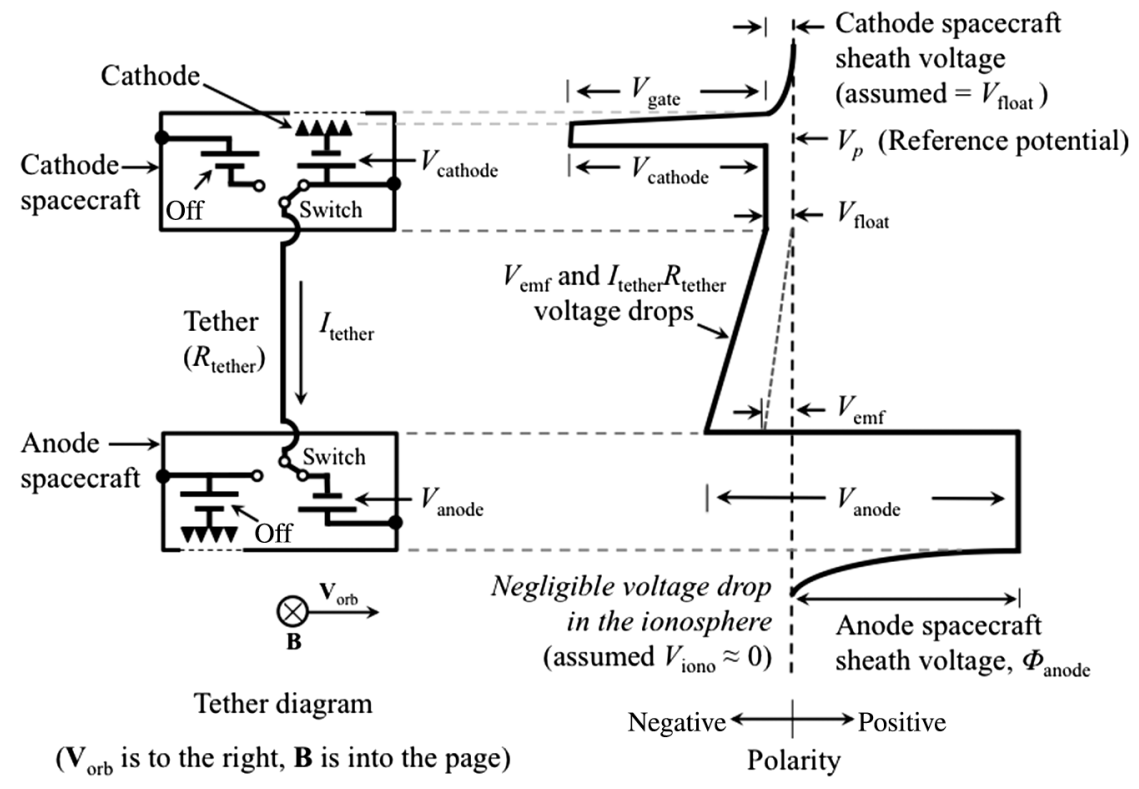

Fig. 3 Electrodynamic tether system and potential diagram for an EDT in a boosting configuration. 
primarily determined by the electron temperature (ignoring factors such as solar UV electron photoemission from the spacecraft surface) [45]. Note that, if the cathode emission current was more or less than the tether current, then the spacecraft would establish a potential that was more positive or more negative than the floating potential, respectively.

\section{Anode Spacecraft}

The anode provides an electrical pathway between the EDT and the ambient plasma by collecting electron current from the ionosphere. The lower spacecraft in Fig. $\underline{3}$ is configured to collect electrons. In this system concept, electrons are collected by the picosat's or femtosat's positively biased (relative to the plasma potential) conducting surfaces exposed to the plasma environment. Since it is assumed that much of the spacecrafts' surface will be covered with solar cells, a transparent conductor (like indium tin oxide, or ITO) can be used to coat the solar cells [61]. It was proposed in [61] that a $\sim 200 \mathrm{~nm}$ layer of ITO would provide sufficient conductivity $(\sim 5 \Omega / \square)$ with a small voltage drop. The current collected by the anode varies, depending on its potential with respect to the ionospheric plasma; the characteristics of the ionosphere; the surface area, geometry, and orientation of the anode; and the specific orbital parameters (e.g., velocity). Simplifying assumptions are made here to facilitate estimating the anode current. For a conductor in an unmagnetized, nondrifting plasma, the sheath surrounding the conductor will expand with increasing bias voltage. If the sheath is large with respect to the conductor, it may conceal the fine details of the anode's shape [62]. Therefore, it is assumed that, at potentials that are high enough, the rectangular cuboid-shaped satellite will collect the current approximately like a sphere with a diameter equal to the spacecraft's longest edge. The equivalent radius of the $200 \mathrm{~g}$ planar picosat, for example, will be $5 \mathrm{~cm}$. To evaluate this assumption, sheath thickness was estimated in [19], revealing a large estimated sheath radius relative to the probe size that helped justify using the spherical collector approximation.

After assuming a spherical collector, an expression was selected that was originally developed to interpret plasma parameters from the Floating Potential Measurement Unit (FPMU) on the International Space Station (ISS) [63]. The FPMU employed the wide-sweeping Langmuir probe instrument (WLP), with a sphere of $5 \mathrm{~cm}$ radius, to do current-voltage $(I-V)$ sweeps in LEO from -20 to $+80 \mathrm{~V}$ (with respect to the local structure potential of the ISS). The expression is [63]

$$
I_{\mathrm{WLP}}=\frac{1}{2} A_{\text {anode }} n_{e} q \sqrt{\frac{k T_{e}}{2 \pi m_{e}}}\left(1+\frac{q\left(V_{\mathrm{anode}}-V_{p}\right)}{k T_{e}}\right)^{\beta}
$$

where $n_{e}$ is electron density, $T_{e}$ is the electron temperature, $m_{e}$ is the electron mass, $A_{\text {anode }}$ is the anode surface area, $V_{p}$ is the plasma potential, and $V_{\text {anode }}$ is the anode power supply potential. It was then fit to current-voltage data in the electron saturation region with different values of the dimensionless parameter $\beta$. In the approximately $2 \mathrm{~h}$ window shown in figure 9 of [63], values of $\beta$ were reported to vary between 0.5 and 1 , and they appeared to be approximately 0.65 when the electron density was similar to the densities assumed in this study at 400 and $500 \mathrm{~km}$, so $\beta=0.65$ is assumed in our model [63]. It was observed in laboratory experiments simulating picosat and femtosat collection in LEO that the WLP approximation calculated current was within a factor of 2-4 of the measured collection current [19]. Efforts to improve this estimate are ongoing.

The ionospheric plasma completes the circuit of an EDT system. The impedance of the ionospheric plasma is very small relative to the anode and cathode impedances [52,53]. The voltage drop in the ionosphere is small because it scales with resistance in the ionosphere and the current in the miniaturized EDT: both of which are relatively small. Thus, we assume the voltage drop in the ionosphere $V_{\text {iono }}$ in Eq. (8) is approximately zero. Additional information on current closure in the ambient plasma can be found in $[\underline{52}, \underline{53}]$.

\section{Estimated Electrical Propulsion Power}

Although EDT propulsion can be propellantless, onboard electrical power is required to generate thrust. In this section, the average propulsion power that can be generated by the $200 \mathrm{~g}$ planar picosat, $150 \mathrm{~g}$ cubic picosat, and $10 \mathrm{~g}$ ChipSat during an orbit is estimated. Power is estimated using the analysis outlined in [8]. Table $\underline{4}$ summarizes the assumptions made in this calculation.

Table 4 Average power generation assumptions and estimate

\begin{tabular}{|c|c|}
\hline Parameter & Value \\
\hline Average solar constant $\Phi_{\text {sun }}$ & $136.8 \mathrm{~mW} \cdot \mathrm{cm}^{-2}$ \\
\hline Average Earth albedo $\Phi_{\text {albedo }}$ & $41.0 \mathrm{~mW} \cdot \mathrm{cm}^{-2}$ \\
\hline Solar cell energy conversion efficiency (triple junction GaAs) $\eta_{\text {conv }}$ & $30 \%$ \\
\hline Efficiency due to cover glass with ITO coating $\eta_{\mathrm{ITO}}$ & 0.9 \\
\hline Total inherent degradation $I_{d}$ & 0.6 \\
\hline Performance degradation per year $D$ & $0.5 \%$ \\
\hline Life degradation $L_{d}$ & 0.98 \\
\hline Average solar angle $\theta_{\text {sun }}$ & $45 \mathrm{deg}$ \\
\hline Average albedo angle $\theta_{\text {albedo }}$ & $45 \mathrm{deg}$ \\
\hline Fraction of the orbit spent in eclipse $T_{\text {ecl }}$ & 0.4 \\
\hline Fraction of the orbit spent in sunlight $T_{d}$ & 0.6 \\
\hline $\begin{array}{l}\text { Efficiency of electrical power distribution from solar array through battery } \\
\text { to spacecraft loads (distribution efficiency during eclipse) } X_{\text {ecl }}\end{array}$ & 0.6 \\
\hline $\begin{array}{l}\text { Efficiency of electrical power distribution from solar array directly to } \\
\text { spacecraft loads (distribution efficiency on the dayside) } X_{d}\end{array}$ & 0.8 \\
\hline Fraction of total generated power available for propulsion $\eta_{\text {prop }}$ & 0.7 \\
\hline $\begin{array}{l}\text { Efficiency of additional voltage boost converter for the anode and } \\
\text { cathode } \eta_{\mathrm{dc}}\end{array}$ & 0.9 \\
\hline \multicolumn{2}{|c|}{ Solar cell area facing the sun, solar cell area facing Earth } \\
\hline $200 \mathrm{~g}$ planar sat & $46 \mathrm{~cm}^{2}$ (sun), $36 \mathrm{~cm}^{2}$ (albedo) \\
\hline $150 \mathrm{~g}$ cubic sat & $32 \mathrm{~cm}^{2}$ (sun), $16 \mathrm{~cm}^{2}$ (albedo) \\
\hline $10 \mathrm{~g}$ ChipSat & $2.5 \mathrm{~cm}^{2}$ (sun), $2.5 \mathrm{~cm}^{2}$ (albedo) \\
\hline \multicolumn{2}{|c|}{ Average propulsion power generated by the pair of spacecraft $P_{\text {prop }}$} \\
\hline $200 \mathrm{~g}$ planar sat pair & $480 \mathrm{~mW}$ \\
\hline $150 \mathrm{~g}$ cubic sat pair & $310 \mathrm{~mW}$ \\
\hline $10 \mathrm{~g}$ ChipSat pair & $27 \mathrm{~mW}$ \\
\hline
\end{tabular}


In this study, it is assumed that solar cells on the outer surface of the spacecraft are used to generate electrical power. At the beginning of life, a solar cell array's power output in sunlight is

$$
P_{\mathrm{BOL}}=\Phi_{\mathrm{sun}} A_{\mathrm{sa}} \eta_{\mathrm{conv}} \eta_{\mathrm{ITO}} I_{d} \cos \left(\theta_{\mathrm{sun}}\right)
$$

where $\Phi_{\text {sun }}$ is the average power per unit area on the surface of a solar cell perpendicular to the sun's rays $\left(\Phi_{\text {sun }}=136.8 \mathrm{~mW} \cdot \mathrm{cm}^{-2}\right) ; A_{\text {sa }}$ is the solar array area; $\theta_{\text {sun }}$ is the incidence angle of the sun measured between the vector normal to the surface of the array and the sun line; $\eta_{\text {conv }}$ is the solar cell energy conversion efficiency; $\eta_{\text {ITO }}$ is the efficiency of the solar cell coating; and $I_{d}$ is the inherent degradation of the solar array [8], which represents effects like heating of the solar cells and reduction in collection area due to interconnect cabling and mounting. A conservative $I_{d}$ of 0.6 is assumed here. Triple-junction gallium arsenide $(\mathrm{GaAs})$ solar cells are considered because they can have a high conversion efficiency of $\sim 30 \%$. In Sec. IV.C, we assume that the solar cell cover glass is coated in ITO to increase the passive current collection area. ITO is the most mature and readily available type of transparent conductive film presently available [64]. If the thickness of the ITO is equal to a half-wavelength of the peak incident solar radiation, then the incident energy at that frequency will be transmitted without attenuation [65]. For incident radiation with half-wavelengths greater than or less than the ITO thickness, the transmission and absorption are given by equation 8 in [65]. Therefore, at peak frequency, the transmission and reflection are governed by the substrate and not the ITO. The transmittance of ITOcoated Corning ${ }^{\circledR}$ Eagle $^{\circledR}$ glass is roughly $90 \%$ at optical frequencies [61], so we assume $\eta_{\text {Iто }}=90 \%$.

It is also necessary to estimate the solar cell area and the solar incidence angle. To estimate the solar cell area, it is assumed that all sides of the $200 \mathrm{~g}$ planar picosat and the $150 \mathrm{~g}$ cubic picosat will have body-mounted solar cells. It is also assumed that, on average during the daylight portion of an orbit, two adjacent sides of each spacecraft will face the sun with an average value of the solar incidence angle (discussed later). Of course, the solar incidence angle for each face will change during the orbit and, at times, three sides or only one side will face the sun; but, for this rough estimate, we assume that, on average, two sides of each spacecraft face the sun with an average value of the solar incidence angle. For the $200 \mathrm{~g}$ satellite, the sunfacing area is one $10 \times 10 \mathrm{~cm}$ face and one $2 \times 10 \mathrm{~cm}$ face. The portion of the total surface area of the $200 \mathrm{~g}$ planar satellite and the $150 \mathrm{~g}$ cubic satellite that can be covered in solar cells is estimated using currently available $2 \times 2 \mathrm{~cm}$ and $1.55 \times 3.18 \mathrm{~cm}$ solar cells [66,67]. The $10 \mathrm{~g}$ ChipSat is much thinner, so it is assumed that it will only have solar cells on its two largest faces, and only one face collects sunlight at a time. The small $10 \mathrm{~g}$ ChipSat will likely require a unique solar cell design, but it is assumed that $~ 50 \%$ of its top and bottom faces can be used for solar collection. The estimated solar array areas are listed in Table 4 . No pointing is assumed, so the average solar angle for body-mounted solar cells is estimated to be $45 \mathrm{deg}$. The same average solar angle is assumed in a similar picosat system concept study for nonpointing body-mounted solar cells on a box-shaped spacecraft [41]. It is also assumed here that the nadirfacing side can generate power from Earth albedo and the average albedo angle will be $45 \mathrm{deg}$.

Solar cell performance degrades over time. This effect, known as life degradation (or $L_{d}$ ), can be estimated as [8]

$$
L_{d}=(1-D)^{L_{i}}
$$

where $L_{i}$ is the spacecraft's lifetime in years, $D$ is the degradation per year, and the life degradation can be thought of as the remaining power production capability of the solar cells at the end of the mission life. For the triple-junction solar arrays assumed here, $D$ is $\sim 0.5 \%$ per year [8]. Generally, such small degradation per year can be ignored; but, here, it is included in the calculation for an estimated five-year lifetime. The resulting life degradation is about $97.5 \%$ for a five-year mission, which means that the solar cell power output decreases by about $2.5 \%$ after five years. The solar array's power output in sunlight at end of life is

$$
P_{\mathrm{EOL}}=P_{\mathrm{BOL}} L_{d}
$$

Using Eq. (13), it was estimated that the $200 \mathrm{~g}$ planar picosat, the $150 \mathrm{~g}$ cubic picosat, and the $10 \mathrm{~g}$ ChipSat could generate 380, 250, and $22 \mathrm{~mW}$ of average power, respectively, in daylight. Naturally, a pair of spacecraft, such as the pair of tethered picosats and femtosats considered in this study, could generate twice as much power. These estimates were consistent (within a factor of three) with the average power generation estimates of other picosat and femtosat concepts $[21,41]$.

To maintain a positive power budget, the power generated in sunlight has to meet the requirements of the spacecraft in daylight and in eclipse. The power that the solar array generates in the daylight can be related to the spacecraft's power demands during daylight and eclipse as [ㅁ]

$$
P_{\mathrm{EOL}}=\left(\frac{P_{\mathrm{ecl}} T_{\mathrm{ecl}}}{X_{\mathrm{ecl}}}+\frac{P_{d} T_{d}}{X_{d}}\right) \frac{1}{T_{d}}
$$

where $T_{d}$ and $T_{\text {ecl }}$ are the fraction of the orbit during daylight and eclipse, respectively; $P_{d}$ and $P_{\mathrm{ecl}}$ are the power demand during daylight and eclipse, respectively; and $X_{d}$ and $X_{\text {ecl }}$ are the distribution and storage efficiencies during daylight and eclipse, respectively. The eclipse time for a spacecraft in a circular orbit of 400-600 km is $\sim 36 \mathrm{~min}$; and the orbital period ranges from about 92-97 $\mathrm{min}$, depending on altitude []. Assuming solar panel peak-powertracking (PPT) power regulation, typical values of the energy conversion efficiency are $X_{\mathrm{ecl}}=0.60$ and $X_{d}=0.80$. A PPT was assumed because it extracts the maximum power from a solar cell array. We also assume that the spacecraft's power demands in daylight and eclipse are approximately equal $\left(P_{d}=P_{\text {ecl }}\right)$.

Here, we estimate the power available to the propulsion subsystem. To estimate the peak thrusting capability of the miniaturized EDT propulsion system, it is assumed that the power available for propulsion represents $70 \%$ of the average power demand during daylight and eclipse (recall, $P_{d}=P_{\text {ecl }}$ ). Expressed as an efficiency, $\eta_{\text {prop }}=70 \%$. In [8], tables $14-20$ provide guidance on power consumption and show that other subsystems, such as the communications, power, and command and data handling systems, require $\sim 30 \%$ of the average power. Our $\eta_{\text {prop }}$ estimate assumes that some subsystems, like thermal management and attitude control, will be passive or require very low average power, which is an assumption made in other small spacecraft studies [41, 68]. Additionally, a separate dc-dc converter is needed to step up the solar array output or battery voltage for the cathode and anode voltages. The efficiency of this power conversion for the anode and cathode $\eta_{\mathrm{dc}}$ is assumed to be $90 \%$ [8]. The resulting propulsion power $P_{\text {prop }}$ can be calculated as $P_{\text {prop }}=\eta_{\mathrm{dc}} \eta_{\text {prop }} P_{d}=\eta_{\mathrm{dc}} \eta_{\text {prop }} P_{\text {ecl }}$.

The average propulsion power generated by the spacecraft can then be expressed as

$$
P_{\text {prop }}=\frac{\Phi_{\text {sun }} A_{\text {sa }} \eta_{\text {conv }} \eta_{\mathrm{dc}} \eta_{\text {prop }} \eta_{\mathrm{ITO}} I_{d} \cos \left(\theta_{\text {sun }}\right)(1-D)^{L_{i}}}{\left(1 / X_{\text {ecl }}\right)\left(T_{\text {ecl }} / T_{d}\right)+\left(1 / X_{d}\right)}
$$

The expression is identical for the sunlight reflected from Earth, except only the Earth-facing solar cell area can be considered and the reflected power per area is about $30 \%$ of direct sunlight [8]. The small energy contribution from Earth infrared radiation is neglected. It is estimated that a pair of $200 \mathrm{~g}$ planar picosats, $150 \mathrm{~g}$ cubic picosats, and the $10 \mathrm{~g}$ ChipSat can generate about 480, 310, and $27 \mathrm{~mW}$ in average propulsion power, respectively.

\section{Electrical Power Required for Drag Makeup}

In this section, we estimate the average power required for drag makeup and compare this to the average power generated for EDT thrust. The electrical power required to drive current through the tether is the sum of the power dissipated in the tether, $I_{\text {tether }}^{2} R_{\text {tether }}$, the power required to overcome emf, $I_{\text {tether }} V_{\text {emf }}$, and the power required to generate the anode sheath voltage, $I_{\text {tether }} \Phi_{\text {anode }}$, and the gate voltage relative to the electron emitting structure for an FEA cathode, 
$I_{\text {tether }} V_{\text {gate }}$. Recall that $\Phi_{\text {anode }}$ is the potential difference between the anode and the ambient plasma. There is also a small potential difference across the sheath traversed by electrons emitted from the cathode; here, this is equal to the spacecraft floating potential $V_{\text {float }}$. The impedance of the plasma is relatively small [52,53], so we ignore it here. Altogether, the total power consumed for EDT propulsion is

$$
P_{\text {EDT }}=I_{\text {tether }}\left(V_{\text {float }}+V_{\text {gate }}+V_{\text {emf }}+I_{\text {tether }} R_{\text {tether }}+\Phi_{\text {anode }}\right)
$$

The power dissipated by the anode and cathode makes up a majority of the electrical demand for the miniature tether application. The ohmic loss in the tether is not dominant because it scales with resistance and the square of current: both of which are relatively small. The emf is also small because miniaturized EDTs are relatively short.

To estimate the tether current needed for drag makeup over a range of possible tether lengths, the EDT thrust was set equal to the drag force, giving

$$
I_{\text {tether }}=\frac{(1 / 2) \rho C_{d} A V_{\text {orb }}}{L B}
$$

which assumes a vertical tether, a perpendicular magnetic field, and thrust that is entirely in plane. Equation (17) was calculated using the average atmospheric density, orbital velocity, and magnetic field strength at 400, 500, and $600 \mathrm{~km}$ altitudes (listed in Table 3), thus providing the average tether current needed for drag makeup. The average power needed for drag makeup is calculated using this value of tether current in Eq. (16).

Initially, to assess the feasibility of drag makeup, the average power required for drag makeup was compared against the average power generated for EDT thrust. Figures $\underline{4 a}-\underline{4 c}$ compare the estimated average spacecraft propulsion power to the estimated average power required for drag makeup. At each altitude considered, there was a tether length that minimized the required drag makeup power. Very short EDTs required a relatively large current to overcome the atmospheric drag force on the spacecraft. At longer lengths, a relatively large current was required to overcome the drag force on the tether. This occurred because, as the tether length increased, the tether radius increased as well, scaling with $L^{3 / 4}$ to prevent severe tether bowing and to ensure some degree of tether semirigidity (discussed in Sec. II.C). The current was minimized when these two effects were balanced. In the case of significant gravity-gradient tension, it was possible to use a much thinner tether that reduced atmospheric drag caused by the EDT and the required drag makeup power.

Boosting may be possible when the pair of femtosats or picosats generate more power for propulsion than needed for drag makeup. All of the spacecraft demonstrate potential to generate sufficient power for drag makeup at 500 and $600 \mathrm{~km}$ altitudes, but the $200 \mathrm{~g}$ planar picosat is the only spacecraft in this study capable of generating power for drag makeup near $400 \mathrm{~km}$. As will be seen, this is consistent with the forces calculated in Sec. VII. The average electrical power required for drag makeup is not shown for the $150 \mathrm{~g}$ cubic picosat at an altitude of $400 \mathrm{~km}$ because the required drag makeup power is beyond the scale of the figure (greater than $1 \mathrm{~W}$ ).

The dominant factors considered here are the area-to-mass ratio of the spacecraft and the surface area for electrical power generation. In the minimum cross-sectional drag area orientation, the $200 \mathrm{~g}$ planar picosat and the $10 \mathrm{~g}$ planar ChipSats have the lowest drag profiles. It is assumed here that the $200 \mathrm{~g}$ planar picosat, however, has more surface area devoted to electrical power generation. This combination of large surface area for propulsion power generation and a low drag profile is the reason the $200 \mathrm{~g}$ planar picosat is able to generate a drag makeup force as low as $400 \mathrm{~km}$. If the spacecraft pairs assessed here are able to generate more power for propulsion than estimated (for example, if the impedances in the tether circuit are less or a thinner radius tether can be used), then either lower altitude drag makeup or boosting to higher altitudes would be possible.

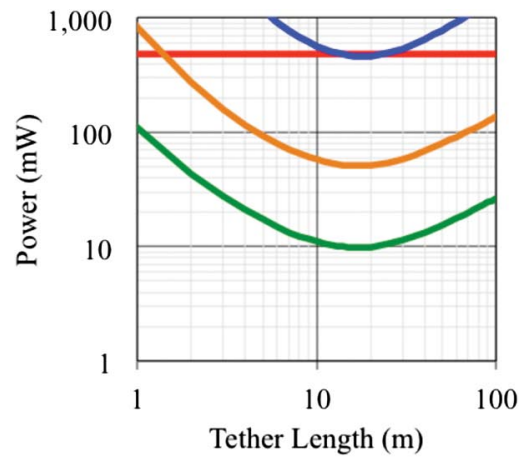

a) 200 g planar picosat

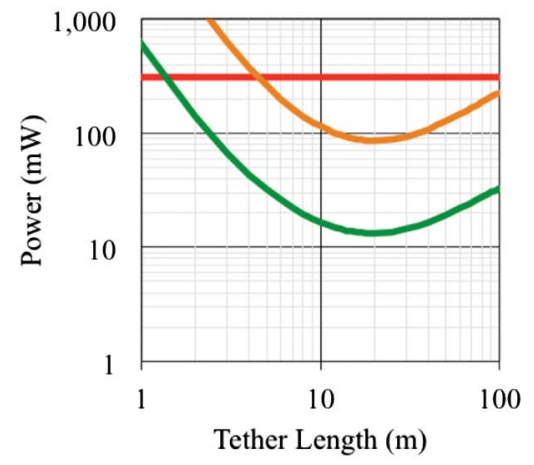

b) 150 g cubic picosat

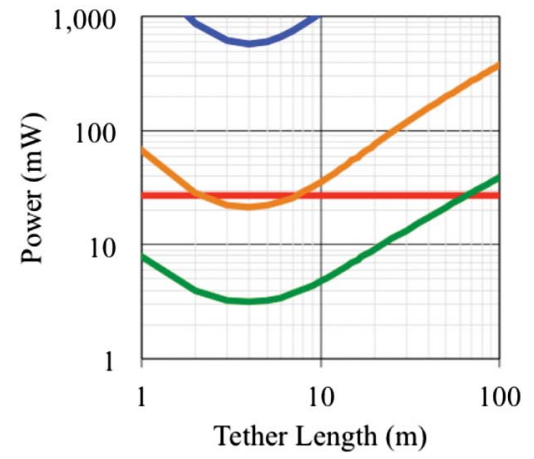

c) $10 \mathrm{~g}$ chipsat

Fig. 4 Estimated average electrical power needed for EDT drag makeup at $400 \mathrm{~km}$ (blue), $500 \mathrm{~km}$ (orange), and $600 \mathrm{~km}$ (green), as well as average electrical propulsion power (red).

\section{EDT Thrust and Other Dominant Forces}

In this section, we evaluate the dominant forces on the miniaturized EDT system. In the altitude range considered here, the atmospheric drag force and the gravity-gradient force are the dominant forces [18]. Figures $5 \mathrm{a}-5 \mathrm{c}$ show average EDT thrust, atmospheric drag, and gravity-gradient force estimates for each spacecraft over a range of tether lengths. Thrust is calculated using Eq. (3), the drag force is calculated using Eq. (5), and the gravity-gradient force is calculated using Eq. (4). In the thrust calculation, it is assumed that the EDT is vertical, perpendicular to the magnetic field, and produces thrust that is entirely in plane. The forces are calculated using the average ionospheric and neutral density parameters listed in Table 3 . The gravity-gradient force decreases with increasing altitude, but the variation from 400 to $600 \mathrm{~km}$ is small, so only one gravity-gradient curve is shown for each tethered spacecraft pair. The solar radiation pressure force is not included because it is below other forces by roughly an order of magnitude at these altitudes [69].

As discussed in Sec. VI, all three spacecraft types appear capable of generating a drag makeup force at 500 and $600 \mathrm{~km}$ altitudes. However, only the $200 \mathrm{~g}$ planar satellite appears able to produce thrust of the same order as drag near $400 \mathrm{~km}$. Tether lengths are 


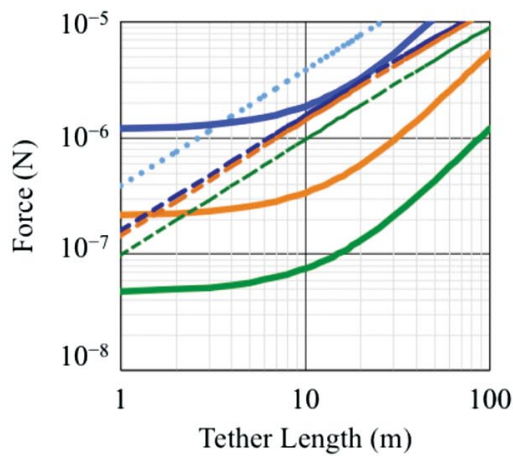

a) 200 g picosat

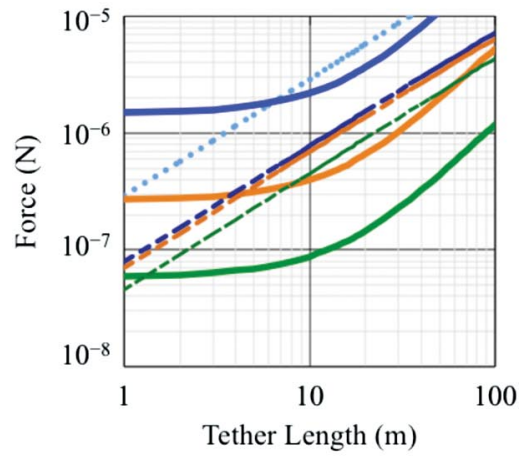

b) 150 g cubic picosat

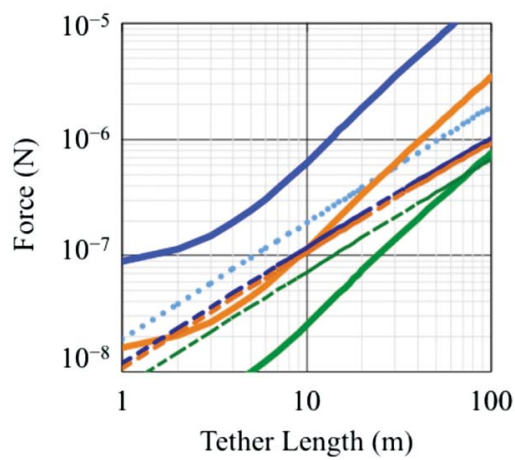

c) $10 \mathrm{~g}$ chipsat

Fig. 5 Estimated average thrust force (dashed lines) and drag force (solid lines) at $400 \mathrm{~km}$ (blue), $500 \mathrm{~km}$ (orange), and $600 \mathrm{~km}$ (green) altitudes. The gravity-gradient force is represented by light blue dotted lines.

selected for each spacecraft to produce the largest thrust-to-drag ratio with the shortest tether. This motivated the choice of a $15-\mathrm{m}$-long tether for the $200 \mathrm{~g}$ planar picosat, a $12 \mathrm{~m}$ tether for the $150 \mathrm{~g}$ cubic picosat, and a $4 \mathrm{~m}$ tether for the $10 \mathrm{~g}$ ChipSat. The tether lengths, mass, radii, and currents are listed in Table 5.

A dominant gravity-gradient force on a tethered spacecraft system suggests a restoring torque that may provide attitude stability. The tethered spacecraft systems with larger, more massive picosats (150 and $200 \mathrm{~g}$ ) generate gravity-gradient forces exceeding other forces at 400,500 , and $600 \mathrm{~km}$. Although the gravity-gradient force is only on the order of a few micronewtons, it is nevertheless dominant relative to the other forces acting on the tethered spacecraft systems. This suggests that the gravity-gradient force may help ensure a degree of stability. For the $10 \mathrm{~g}$ ChipSat, the gravity-gradient force only appears to be dominant at 500 and $600 \mathrm{~km}$. It may be possible for the $10 \mathrm{~g}$ ChipSat to use multiple tethers on several axes if attitude stability is not feasible [70,71].

Realistically, the EDT may not be perpendicular to the magnetic field throughout an orbit due to the orbital inclination or EDT librations. If the EDT is not perpendicular to the magnetic field, inplane thrust will be reduced and the EDT will produce an out-of-plane thrust component. In [19], figure 5.10 showed the reduction of inplane thrust at higher inclination orbits. For example, EDT in-plane thrust in a 45-deg-inclination circular 400-km-altitude orbit was about $60 \%$ less than in-plane thrust in an equatorial orbit (assuming no libration and a vertical EDT) [19]. Thus, it will be important in future studies to investigate this propulsion concept in a variety of inclinations, altitudes, and solar conditions. It will also be important to study the effect of the tether dynamics on these small, tethered spacecraft pairs. There are other potential effects that have been investigated for longer tethers, including instabilities pumped by the variation of thrusting around the orbit, and these should also be investigated at the smaller scale [ㄹ].

\section{Orbital Maneuvering Simulation Results and Analysis}

The Tethered Mission Planning and Evaluation Software Tool (TeMPEST) allows the EDT system to be simulated in orbit. TeMPEST incorporates geomagnetic field models, ionospheric and atmospheric conditions, plasma contactor modeling, and precise orbital calculations to predict propulsion performance [73]. The version of TeMPEST used to simulate tether propulsion in this paper used the MSIS-E-90, IRI-90, and IGRF-91 models [48-50]. The IRI90 and IGRF-91 are earlier versions of the IRI and IGRF models discussed in Sec. III.C.

The simulations were initiated on 1 January 2000, which was during a solar maximum, so the heightened neutral-to-electrondensity ratio presented a worst-case scenario for EDT thrusting (Sec. III.C). The simulations were initiated on 1 January 2000 instead of the date used in the trade study of 1 July 2011, because 1) the ionosphere and neutral atmosphere conditions were similar on both dates and 2) the older IRI-90 model could simulate the ionospheric conditions in 2000 more accurately than in 2011. Unlike the average orbital environment parameters used earlier in the study, the parameters in TeMPEST were calculated at the location of the spacecraft in each simulation time step (here, $30 \mathrm{~s}$ ). The simulations were also performed assuming a 0 deg inclination orbit that was initially circular. The tether dimensions and propulsion power used in the simulation are listed in Table 5. The TeMPEST simulations did not incorporate tether libration, so the tether was assumed to be straight and vertically oriented throughout the orbit. Although these effects were not studied here, it will be important to incorporate attitude dynamics in future tether system simulations.

TeMPEST was used to generate Figs. $6 \mathrm{a}-6 \mathrm{c}$. The figures show the change in altitude of individual spacecraft without propulsion in orange at 400,500, and $600 \mathrm{~km}$ starting altitudes. Rapid orbital decay due to atmospheric drag can be seen without an EDT at a $400 \mathrm{~km}$ starting altitude. The atmosphere is much more tenuous at 500 and $600 \mathrm{~km}$, so orbital decay occurs much more slowly. In the same set of figures, the change in altitude for an EDT providing an orbit-raising propulsion force to a tethered pair of spacecraft is shown in blue. The figures show drag makeup and boosting capability at 500 and $600 \mathrm{~km}$

Table 5 System concept summary

\begin{tabular}{lccc}
\hline \hline Parameter & $\begin{array}{c}200 \mathrm{~g} \text { planar } \\
\text { picosat }\end{array}$ & $\begin{array}{c}150 \mathrm{~g} \text { cubic } \\
\text { picosat }\end{array}$ & $\begin{array}{c}10 \mathrm{~g} \\
\text { ChipSat }\end{array}$ \\
\hline Average propulsion power & $480 \mathrm{~mW}$ & $310 \mathrm{~mW}$ & $27 \mathrm{~mW}$ \\
Tether length & $15 \mathrm{~m}$ & $12 \mathrm{~m}$ & $4 \mathrm{~m}$ \\
Tether radius & $130 \mu \mathrm{m}$ & $140 \mu \mathrm{m}$ & $51 \mu \mathrm{m}$ \\
Tether mass & $5.6 \mathrm{~g}$ & $5.3 \mathrm{~g}$ & $190 \mathrm{mg}$ \\
Estimated peak tether current & & & \\
$\quad 400 \mathrm{~km}$ & $5.2 \mathrm{~mA}$ & $2.6 \mathrm{~mA}^{\mathrm{a}}$ & $395 \mu \mathrm{A}^{\mathrm{a}}$ \\
$500 \mathrm{~km}$ & $4.7 \mathrm{~mA}$ & $2.3 \mathrm{~mA}$ & $360 \mu \mathrm{A}$ \\
$600 \mathrm{~km}$ & $3.2 \mathrm{~mA}$ & $1.5 \mathrm{~mA}$ & $243 \mu \mathrm{A}$ \\
Estimated peak thrust force & & & \\
$400 \mathrm{~km}$ & $2.3 \mu \mathrm{N}$ & $0.9 \mu \mathrm{Na}$ & $47 \mathrm{nN}$ \\
$500 \mathrm{~km}$ & $2.1 \mu \mathrm{N}$ & $0.8 \mu \mathrm{N}$ & $43 \mathrm{nN}$ \\
$\quad 600 \mathrm{~km}$ & $1.5 \mu \mathrm{N}$ & $0.5 \mu \mathrm{N}$ & $29 \mathrm{nN}$ \\
Gravity-gradient force & $5.8 \mu \mathrm{N}$ & $3.5 \mu \mathrm{N}$ & $77 \mathrm{nN}$ \\
\hline \hline
\end{tabular}

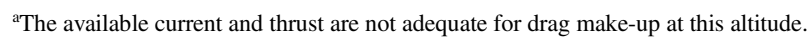




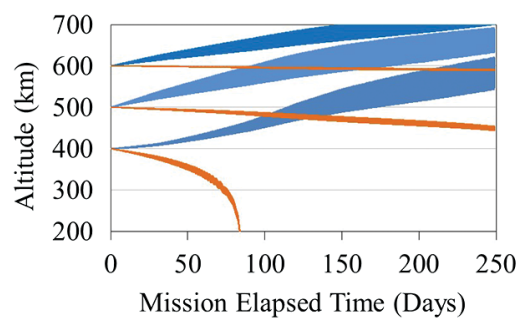

a) 200 g planar picosat

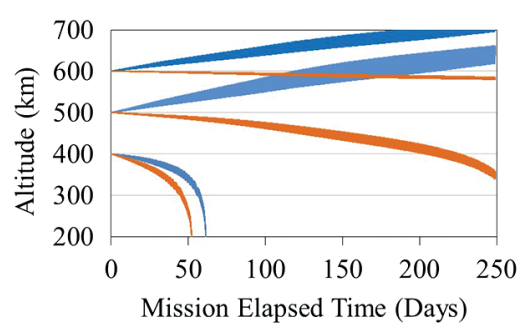

b) 150 g cubic picosat

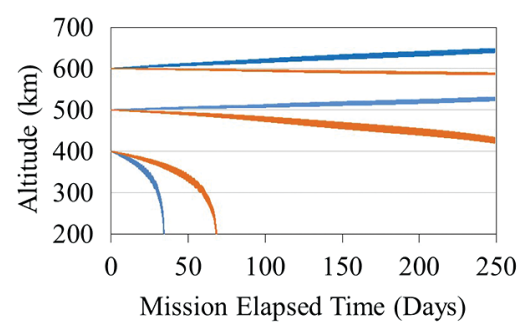

c) $10 \mathrm{~g}$ chipsat

Fig. 6 Simulation of altitude change for a single spacecraft (orange) starting at 400, 500, and $600 \mathrm{~km}$ compared with dual tethered spacecraft with an EDT providing a boosting force (blue).

starting altitudes. The tethered $200 \mathrm{~g}$ planar picosats also show the potential of boosting at a $400 \mathrm{~km}$ starting altitude, which is consistent with results from Secs. VI and VII. It should be noted that, in Fig. 6c, at a starting altitude of $400 \mathrm{~km}$, a pair of $10 \mathrm{~g}$ ChipSats with a miniaturized EDT loses altitude more rapidly than a $10 \mathrm{~g}$ ChipSat without one. Specifically, the simulation shows the dual tethered $10 \mathrm{~g}$ ChipSats deorbit faster by a few days. The tethered system deorbits because the EDT cannot generate a drag makeup force at this altitude (again, this is consistent with results from Secs. VI and VII). At a $400 \mathrm{~km}$ starting altitude, the magnitude of thrust generated by the pair of tethered $10 \mathrm{~g}$ ChipSats is about $10 \%$ of the atmospheric drag force (Sec. VII.C). The miniaturized EDT also has a higher area-to-mass ratio than the tethered femtosats it connects. As a result, the EDT increases the area-to-mass ratio of the overall tethered spacecraft system, causing the thrusting tethered $10 \mathrm{~g}$ ChipSat pair to deorbit more rapidly than the individual spacecraft.

And, although the focus here has been drag makeup and boosting, figure 3.15 of [19] depicted the change in altitude for tethered spacecraft using a miniaturized EDT to produce a deboosting force. By driving current in the opposite direction of that shown in Fig. 3 , the EDT produced thrust in the direction opposite the spacecraft motion, which removed energy from the orbit and deboosted the spacecraft. The TeMPEST simulations in [19] showed that a miniaturized EDT could deorbit the tethered picosats and femtosats in four to nine months from a $600 \mathrm{~km}$ starting altitude and in one to three months from 400 and $500 \mathrm{~km}$ starting altitudes [19]. Altogether, these results highlight the potential of miniaturized EDT technology to provide small spacecraft with enhanced maneuverability.

Although the altitude curves in Fig. 6a-6c appear to widen, this only represents increasing eccentricity of the orbit over time. The effect is particularly pronounced for EDTs that are continuously boosting (which is the case here). The thrust force increases in regions of the ionosphere where the electron density is higher, and the uneven thrust in each orbit results in an increasing orbital eccentricity.
However, EDT boosting can be planned so the satellite orbit eccentricity degradation is minimized [28].

\section{Miniaturized Tether Electrodynamics Experiment}

The Miniaturized Tether Electrodynamics Experiment (MiTEE) is being planned at the University of Michigan. The MiTEE is a set of student-led technology-demonstration missions that will use nanosatellite capabilities to deploy a tethered picosatellite on a fixed boom and evaluate the basic tether dynamics and plasma electrodynamics fundamental to a miniaturized EDT's operation in orbit. The first MiTEE mission will begin to address the risk reduction of the EDT dynamics, which is critical to enhancing our understanding of the behavior of the miniaturized EDT system in the orbital environment. This provides an opportunity to investigate the impact of the gravity-gradient force and torque on the miniaturized EDT system. In later experiments, the tethered picosatellite will be deployed without the fixed boom and allow the mission to study EDT dynamics. Although the first MiTEE mission will use thermionic electron emission technology, later experiments will use an FEA cathode or another low-power electron emitter. These missions will provide an opportunity to enhance our understanding of the miniaturized EDT concept in the orbital environment and drive down the risk of key components of the concept.

\section{Conclusions}

The potential of EDT technology to enhance picosat and femtosat maneuverability is investigated. Using tethered picosats and femtosats with advanced, miniaturized low-power electronics and sensors, it is possible to create dynamically maneuverable and reconfigurable fleets of subkilogram smartphone-sized spacecraft. There is a variety of potential applications that could benefit from this capability, including mission concepts requiring a coordinated, controlled fleet of microspacecraft distributed in space and/or time.

A detailed trade study was conducted to evaluate the ability of miniaturized EDTs to enable picosats and femtosats in the orbital environment. Based on a set of power-generation estimates, the $200 \mathrm{~g}$ planar picosat, the $150 \mathrm{~g}$ cubic picosat, and the $10 \mathrm{~g}$ ChipSat showed the potential to generate a thrust force capable of propellantless drag makeup and boosting at 500 and $600 \mathrm{~km}$ altitudes in an equatorial orbit with an EDT only a few meters in length. Only the $200 \mathrm{~g}$ planar picosat showed the potential to generate a thrust force exceeding atmospheric drag near $400 \mathrm{~km}$. The system concept was also capable of reversing the direction of thrust and deboosting the spacecraft. The results presented here can be used to help mission designers evaluate the benefit of this technology for specific mission scenarios.

There are several other topics that will need to be investigated further to more completely demonstrate the feasibility of the concept. There are important practical questions that need to be addressed regarding tether storage, deployment, and dynamics on orbit. Also, although this study compares the magnitudes of the dominant forces on the spacecraft, the complex interaction of these forces will ultimately determine the spacecraft's ability to thrust and influence its attitude. There is also a need for a more detailed study considering the effect of the nonlinear environmental forces on these small spacecraft. The forces that are most relevant to spacecraft at this uniquely small size and mass scale were discussed in [18], but there is still a need to investigate their impact on the maneuverability of these spacecraft. In addition, the electron field emission technology considered here is extremely sensitive to surface contamination, so storage on the ground and in operation in LEO needs to be considered.

Moreover, it will also be important to explore the performance of miniaturized EDT systems in specific mission scenarios. References $[10,17]$ provided examples of meaningful missions that spacecraft at this size and mass scale could potentially accomplish. It will be important in future studies to investigate specific mission scenarios in order to better understand the ability of miniaturized EDTs to enhance picosat and femtosat capabilities. Even with these questions, this study suggests that the miniaturized EDT concept has the potential to enable small satellite maneuverability. 


\section{Acknowledgments}

The authors gratefully acknowledge support from the U.S. Air Force Office of Scientific Research grant FA9550-09-1-0646, the National Science Foundation Graduate Student Research Fellowship under grant no. DGE 1256260, the Michigan Space Grant Consortium, and the Michigan Institute for Plasma Science and Engineering. I.C. Bell also thanks J. Rager for guidance in performing the tether semirigidity analysis and all of the students who worked with the Miniaturized Tether Electrodynamics Experiment mission for their assistance in developing this concept.

\section{References}

[1] Selva, D., and Krejci, D., "A Survey and Assessment of the Capabilities of Cubesats for Earth Observation," Acta Astronautica, Vol. 74, May 2012, pp. 50-68. doi:10.1016/j.actaastro.2011.12.014

[2] Bouwmeester, J., and Guo, J., "Survey of Worldwide Pico- and Nanosatellite Missions, Distributions and Subsystem Technology," Acta Astronautica, Vol. 67, Nos. 7-8, Oct. 2010, pp. 854-862. doi:10.1016/j.actaastro.2010.06.004

[3] Jähnichen, S., Brie $\beta$, K., and Burmeister, R., "Flying Sensors-Swarms in Space," Autonomous Systems-Self-Organization, Management, and Control, Springer, New York, 2008, pp. 71-77.

[4] Keller, J., "Startup to Develop Satellite-On-A-Chip," Military Aerospace Electronics, Vol. 5, No. 2, 1994, p. 1.

[5] Huang, A., Hansen, W. W., Janson, S. W., and Helvajian, H., "Development of a 100-gm-Class Inspector Satellite Using Photostructurable Glass/Ceramic Materials," Vol. 4637, 2002, pp. 297-304.

[6] Janson, S. W., Helvajian, H., and Breuer, K., "MEMS, Microengineering and Aerospace Systems," AIAA Paper 1999-3802, 1999.

[7] Barnhart, D. J., Vladimirova, T., and Sweeting, M. N., "Satellite Miniaturization Techniques for Space Sensor Networks," Journal of Spacecraft and Rockets, Vol. 46, No. 2, 2009, pp. 469-472. doi:10.2514/1.41639

[8] Wertz, J. R., Everett, D. F., and Puschell, J. J., Space Mission Engineering: The New SMAD, Microcosm Press, Hawthorne, CA, 2011, pp. 500-700.

[9] "Small Spacecraft Technology State of the Art," Mission Design Division Staff, NASA Ames Research Center TP NASA/TP-2014216648/REV1, Moffett Field, CA, Jan. 2014.

[10] Barnhart, D. J., Vladimirova, T., Baker, A. M., and Sweeting, M. N., "A Low-Cost Femtosatellite to Enable Distributed Space Missions," Acta Astronautica, Vol. 64, Nos. 11-12, June 2009, pp. 1123-1143. doi:10.1016/j.actaastro.2009.01.025

[11] Vladimirova, T., Sweeting, M. N., Vitanov, I., and Vitanov, V. I., "Emergency Response Networks for Disaster Monitoring and Detection from Space," SPIE Defense, Security, and Sensing, 2009, Paper $73470 \mathrm{~N}$.

[12] Tristancho Martínez, J., and Gutierrez Cabello, J. L., "Simplified FemtoSatellite Operations for Disaster Management Missions," 2012.

[13] Krause, L. H., Enloe, C. L., Haaland, R. K., and Golando, P., "Microsatellite Missions to Conduct Midlatitude Studies of Equatorial Ionospheric Plasma Bubbles," Advances in Space Research, Vol. 36, No. 12,2005 , pp. 2474-2479. doi:10.1016/j.asr.2004.03.020

[14] Bandyopadhyay, S., Subramanian, G. P., Foust, R., Morgan, D., Chung, S.-J., and Hadaegh, F., "A Review of Impending Small Satellite Formation Flying Missions," 53rd AIAA Aerospace Sciences Meeting, AIAA Paper 2015-1623, 2015.

[15] de las Heras López, Á., "Design and Implementation of a Synthetic Aperture Antenna for a Femto-Satellite,” 2011.

[16] Hadaegh, F. Y., Chung, S.-J., and Manohara, H. M., "On Development of 100-Gram-Class Spacecraft for Swarm Applications," 2013.

[17] Janson, S., and Barnhart, D., "The Next Little Thing: Femtosatellites," AIAA/USU Small Satellite Conference, AIAA, Reston, VA, Aug. 2013, Paper SSC13-VI-3.

[18] Atchison, J. A., and Peck, M. A., "Length Scaling in Spacecraft Dynamics," Journal of Guidance, Control, and Dynamics, Vol. 34, No. 1, 2011, pp. 231-246. doi:10.2514/1.49383

[19] Bell, I. C., "A System Concept Study and Experimental Evaluation of Miniaturized Electrodynamic Tethers to Enhance Picosatellite and Femtosatellite Capabilities," Ph.D. Dissertation, Dept. of Electrical Engineering and Computer Science, Univ. of Michigan, Ann Arbor, MI, 2015.
[20] Wright, W. P., and Ferrer, P., "Electric Micropropulsion Systems," Progress in Aerospace Sciences, Vol. 74, April 2015, pp. 48-61. doi:10.1016/j.paerosci.2014.10.003

[21] Atchison, J. A., and Peck, M. A., "A Passive, Sun-Pointing, MillimeterScale Solar Sail," Acta Astronautica, Vol. 67, Nos. 1-2, July 2010, pp. 108-121. doi:10.1016/j.actaastro.2009.12.008

[22] Lücking, C., Colombo, C., and McInnes, C. R., "Electrochromic Orbit Control for Smart-Dust Devices," Journal of Guidance, Control, and Dynamics, Vol. 35, No. 5, 2012, pp. 1548-1558. doi: $10.2514 / 1.55488$

[23] Peck, M. A., Streetman, B., Saaj, C. M., and Lappas, V., "Spacecraft Formation Flying Using Lorentz Forces," Journal of the British Interplanetary Society, Vol. 60, 2007, pp. 263-267.

[24] Bilen, S. G., McTernan, J. K., Gilchrist, B. E., Bell, I. C., Liaw, D., Voronka, N. R., and Hoyt, R. P., "Energy Harvesting on Spacecraft Using Electrodynamic Tethers," 2012.

[25] Banks, P. M., "Review of Electrodynamic Tethers for Space Plasma Science," Journal of Spacecraft and Rockets, Vol. 26, No. 4, July 1989, pp. 234-239. doi: $10.2514 / 3.26060$

[26] Williams, S. D., Gilchrist, B. E., Agüero, V. M., Indiresan, R. S., Thompson, D. C., and Raitt, W. J., "TSS-1R Vertical Electric Fields: Long Baseline Measurements Using an Electrodynamic Tether as a Double Probe," Geophysical Research Letters, Vol. 25, No. 4, Feb. 1998, pp. 445-448. doi:10.1029/97GL03259

[27] Kelley, M. C., The Earth's Ionosphere: Plasma Physics and Electrodynamics, Vol. 96, Academic Press, New York, 2009, pp. 237-254.

[28] Cosmo, M. L., and Lorenzini, E. C. (eds.), Tethers in Space Handbook, Vol. 4, NASA, 1997.

[29] Sanmartin, J. R., Ahedo, E., Conde, L., Pelaez, J., Ruiz, M., Weinberger, M., and Hilgers, A., "Short Electrodynamic Tethers," Spacecraft Charging Technology, Vol. 476, 2001, pp. 581-585.

[30] Estes, R. D., Lorenzini, E. C., and Sanmartín Losada, J. R., "Short Tethers for Electrodynamic Thrust," 2002.

[31] Pernicka, H. J., Dancer, M., Abrudan, A., and Harrington, J., "Simulation of the Dynamics of a Short Tethered Satellite System," 2004.

[32] Valverde, J., Escalona, J. L., Mayo, J., and Domínguez, J., "Dynamic Analysis of a Light Structure in Outer Space: Short Electrodynamic Tether," Multibody System Dynamics, Vol. 10, No. 1, 2003, pp. 125-146. doi:10.1023/A:1024527924176

[33] Zhong, R., and Zhu, Z. H., "Dynamics of Nanosatellite Deorbit by Bare Electrodynamic Tether in Low Earth Orbit," Journal of Spacecraft and Rockets, Vol. 50, No. 3, 2013, pp. 691-700. doi:10.2514/1.A32336

[34] Sanmartin, J. R., Lorenzini, E. C., and Martinez-Sanchez, M., "Electrodynamic Tether Applications and Constraints," Journal of Spacecraft and Rockets, Vol. 47, No. 3, 2010, pp. 442-456. doi: $10.2514 / 1.45352$

[35] Bell, I., Gilchrist, B., McTernan, J., Bilen, S., Hoyt, R. P., Voronka, N. R., and Mason, P., "The Potential of Miniature Electrodynamic Tethers to Enhance Capabilities of Femtosatellites," 32nd International Electric Propulsion Conference, IEPC Paper 2011-054, Wiesbaden, Germany, 2011.

[36] Gere, J. M., and Timoshenko, S. P., Mechanics of Materials, Brooks/ Cole, Pacific Grove, CA, 2001, pp. 815-839.

[37] "Monel Alloy K-500," SMC-062, Sept. 2004.

[38] Jensen, J. E., Stewart, R. G., Tuttle, W. A., and Brechna, H., Brookhaven National Laboratory Selected Cryogenic Data Notebook: Sections X-XVIII, Vol. 2, Brookhaven National Lab., Upton, NY, 1980, Paper XIC-3.6.

[39] deGroh, K., Banks, B. A., McCarthy, C. E., Rucker, R. N., Roberts, L. M., and Berger, L. A."MISSE PEACE Polymers Atomic Oxygen Erosion Results," NASA Rept. NASA/TM-2006-214482, 2006, http://www. academia.edu/2924456/MISSE_PEACE_Polymers_atomic_oxygen_ erosion_results [retrieved 31 March 2015].

[40] "PFA Coating; PFA Film I DuPontTM Teflon ® PFA," DuPont Properties Bulletin E80419, Wilmington, DE, Dec. 1985.

[41] Barnhart, D. J., Vladimirova, T., and Sweeting, M. N., "Very-SmallSatellite Design for Distributed Space Missions," Journal of Spacecraft and Rockets, Vol. 44, No. 6, 2007, pp. 1294-1306. doi: $10.2514 / 1.28678$

[42] Zack, K., Jernigan, J. G., and Cominsky, L., "The Development of a 3P PocketQube," Bulletin of the American Physical Society, Vol. 58, 2013, pp. 58-59. 
[43] Manchester, Z., Peck, M., and Filo, A., "KickSat: A Crowd-Funded Mission to Demonstrate the World's Smallest Spacecraft," AIAA/USU Small Satellite Conference, AIAA, Reston, VA, Aug. 2013, Paper SSC13-IX-5.

[44] Atchison, J. A., and Peck, M., "A Passive Microscale Solar Sail," AIAA SPACE 2008 Conference and Exposition, AIAA Paper 2008-7840, 2008.

[45] Hastings, D., and Garrett, H., Spacecraft-Environment Interactions, Cambridge Univ. Press, Cambridge, England, U.K., 2004, pp. 53-65.

[46] Hill, T. W., "Inertial Limit on Corotation," Journal of Geophysical Research Space Physics 1978-2012, Vol. 84, No. A11, 1979, pp. 6554-6558. doi:10.1029/JA084iA11p06554

[47] Bilén, S. G., "Pulse Propagation Along Conductors in Low-Density, Cold Plasmas as Applied to Electrodynamic Tethers in the Ionosphere," Ph.D. Dissertation, Univ. of Michigan, Ann Arbor, MI, 1998.

[48] Hedi, A. E., "Extension of the MSIS Thermospheric Model into the Middle and Lower Atmosphere," Journal of Geophysical Research, Vol. 96, No. A2, 1991, pp. 1159-1172. doi:10.1029/90JA02125

[49] Macmillan, S., and Maus, S., "International Geomagnetic Reference Field-The Tenth Generation," Earth Planets Space, Vol. 57, No. 12, June 2014, pp. 1135-1140. doi:10.1186/BF03351896

[50] Bilitza, D., McKinnell, L.-A., Reinisch, B., and Fuller-Rowell, T., "The International Reference Ionosphere Today and in the Future," Journal of Geodesy, Vol. 85, No. 12, 2011, pp. 909-920. doi:10.1007/s00190-010-0427-x

[51] Hathaway, D. H., and Suess, S. T., "Solar Cycle 23," The Heliosphere Through the Solar Activity Cycle, Springer, Berlin, 2008, pp. 21-39.

[52] Estes, R. D., "Alfven Waves from an Electrodynamic Tethered Satellite System," Journal of Geophysical Research Space Physics 1978-2012, Vol. 93, No. A2, 1988, pp. 945-956. doi:10.1029/JA093iA02p00945

[53] Hastings, D. E., and Wang, J., "The Radiation Impedance of an Electrodynamic Tether with End Connectors," Geophysical Research Letters, Vol. 14, No. 5, 1987, pp. 519-522. doi:10.1029/GL014i005p00519

[54] Koeck, F. A. M., Nemanich, R. J., Lazea, A., and Haenen, K., "Thermionic Electron Emission from Low Work-Function Phosphorus Doped Diamond Films," Diamond and Related Materials, Vol. 18, Nos. 5-8, May 2009, pp. 789-791. doi:10.1016/j.diamond.2009.01.024

[55] Okawa, Y., Kitamura, S., Kawamoto, S., Iseki, Y., Hashimoto, K., and Noda, E., "An Experimental Study on Carbon Nanotube Cathodes for Electrodynamic Tether Propulsion," Acta Astronautica, Vol. 61, Nos. 11-12, Dec. 2007, pp. 989-994. doi:10.1016/j.actaastro.2006.12.017

[56] Spindt, C. A., "A Thin-Film Field-Emission Cathode," Journal of Applied Physics, Vol. 39, No. 7, June 1968, pp. 3504-3505. doi:10.1063/1.1656810

[57] Williams, L. T., Kumsomboone, V. S., Ready, W. J., and Walker, M. L. R., "Lifetime and Failure Mechanisms of an Arrayed Carbon Nanotube Field Emission Cathode," IEEE Transactions on Electron Devices, Vol. 57, No. 11, Nov. 2010, pp. 3163-3168. doi:10.1109/TED.2010.2069563

[58] Marrese, C. M., Gallimore, A. D., Mackie, W. A., and Evans, D. E., "The Design of a Cathode to Operate in an Oxygen-Rich Environment," 1997.

[59] Whaley, D. R., Duggal, R., Armstrong, C. M., Bellew, C. L., Holland, C. E., and Spindt, C. A., "100 W Operation of a Cold Cathode
TWT," IEEE Transactions on Electron Devices, Vol. 56, No. 5, 2009, pp. 896-905.

doi:10.1109/TED.2009.2015614

[60] Morris, D. P., "Optimizing Space-Charge Limits of Electron Emission into Plasmas with Application to In-Space Electric Propulsion," Ph.D. Dissertation, Univ. of Michigan, Ann Arbor, MI, 2005.

[61] McTernan, J. K., Brubaker, T. R., and Bilén, S. G., "Indium Tin Oxide Coverings on Solar Panels for Plasma-Spacecraft Connection," IEEE 39th Photovoltaic Specialists Conference (PVSC), IEEE, Piscataway, NJ, 2013, pp. 2821-2826.

[62] Whipple, E. C., "Theory of the Spherically Symmetric Photoelectron Sheath: AThick Sheath Approximation and Comparison with the ATS 6 Observation of a Potential Barrier," Journal of Geophysical Research, Vol. 81, No. 4, Feb. 1976, pp. 601-607.

[63] Barjatya, A., Swenson, C. M., Thompson, D. C., and Wright, K. H., "Invited Article: Data Analysis of the Floating Potential Measurement Unit aboard the International Space Station," Review of Scientific Instruments, Vol. 80, No. 4, April 2009, Paper 41301. doi:10.1063/1.3116085

[64] Hecht, D. S., Hu, L., and Irvin, G., "Emerging Transparent Electrodes Based on Thin Films of Carbon Nanotubes, Graphene, and Metallic Nanostructures," Advanced Materials, Vol. 23, No. 13, April 2011, pp. 1482-1513. doi:10.1002/adma.201003188

[65] Chiou, B.-S., and Tsai, J.-H., "Antireflective Coating for ITO Films Deposited on Glass Substrate," Journal of Materials Science: Materials in Electronics, Vol. 10, No. 7, Sept. 1999, pp. 491-495.

[66] Vertat, I., Hrouda, J., and Hofman, J., "Spectrolab Triangular Solar Cell Evaluation for Usage in PilsenCUBE Picosatellite," International Conference on Applied Electronics (AE), IEEE, New York, 2010, pp. $1-4$.

[67] Clark, C. S., "An Advanced Electrical Power System for Cubesats," European Small Satellite Services Symposium, Vol. 31, ESA, 2010.

[68] Ekpo, S. C., and George, D., "A System Engineering Analysis of Highly Adaptive Small Satellites," IEEE Systems Journal, Vol. 7, No. 4, 2013, pp. 642-648. doi:10.1109/JSYST.2012.2198138

[69] Bell, I., Gilchrist, B., Bilén, S., and McTernan, J., "Investigating the Use of Miniaturized Electrodynamic Tethers to Enhance the Capabilities of Femtosatellites and other Ultra-Small Satellites," 2012.

[70] Voronka, N. R., Hoyt, R. P., Slostad, J., Gilchrist, B. E., and Fuhrhop, K., "Modular Spacecraft with Integrated Structural Electrodynamic Propulsion," NASA, Inst. for Advanced Concepts Rept. NAS503110-07605-003-050, 2006.

[71] Weis, L., and Peck, M., "Attitude Control for Chip Satellites Using Multiple Electrodynamic Tethers," AIAA/AAS Astrodynamics Specialist Conference, AIAA Paper 2012-4871, 2012.

[72] Corsi, J., and Iess, L., "Stability and Control Of Electrodynamic Tethers for De-Orbiting Applications," Acta Astronautica, Vol. 48, No. 5, 2001, pp. 491-501. doi:10.1016/S0094-5765(01)00049-2

[73] Bilén, S. G., McTernan, J. K., Gilchrist, B. E., Bell, I. C., Voronka, N. R., and Hoyt, R. P., "Electrodynamic Tethers for Energy Harvesting and Propulsion on Space Platforms," AIAA SPACE 2010 Conference and Exposition, AIAA Paper 2010-8844, Aug.-Sept. 2010.

E. G. Lightsey Associate Editor 